\title{
Sistem Monitoring Resource pada Jaringan FMIPA Unesa dengan Protocol SNMP
}

\author{
Asmunin, Wahyu Khamdani \\ Jurusan Teknik Informatika \\ Fakultas Teknik \\ Universitas Negeri Surabaya \\ asmunin@unesa.ac.id, wahyu.khamdani@yahoo.co.id
}

Diterima: 9 Maret 2016. Disetujui: 11 April 2016. Dipublikasikan: Mei 2016

\begin{abstract}
Abstrak - Kualitas layanan jaringan komputer yang tertuang dalam SLA (Service Level Agreement) harus tetap dijaga seiring jumlah pengguna yang semakin banyak. Dua hal penting yang menjadi ukuran kualitas jaringan adalah kecepatan akses dan kestabilan sehingga perlu selalu dimonitor sehingga jika terjadi gangguan dapat segera diketahui dan diperbaiki. Pada jaringan FMIPA Unesa, kedua ukuran kualitas tersebut harus selalu diawasi setiap waktu agar kualitas yang tertuang dalam SLA dapat tercapai. Umumnya, monitoring jaringan hanya memakai tools yang sudah ada pada perangkat jaringan, seperti MRTG. Salah satu kelemahannya adalah ketika perangkat down, maka hasil monitor oleh perangkat juga akan hilang karena tidak tersimpan pada harddisk. Untuk mengatasi hal tersebut maka diterapkan sebuah sistem monitoring jaringan berbasis SNMP dengan aplikasi Cacti, yang melakukan monitoring kondisi jaringan setiap waktu. Hasil pengujian menunjukkan bahwa setelah dilakukan monitoring jaringan berbasis SNMP dengan aplikasi Cacti, dapat memonitor jaringan dan bandwidth pada banyak perangkat sekaligus, dapat menampilkan grafik yang rinci seperti traffic, resource, dan uptime, dapat memberikan notifikasi email, dan juga dapat menghasilkan pemetaan jaringan, serta data hasil monitoring dapat tersimpan.
\end{abstract}

Kata Kunci: monitoring jaringan; SNMP; Cacti.

\section{PENDAHULUAN}

Seringkali karena banyaknya pengguna yang terhubung pada jaringan dapat menyebabkan jaringan menjadi tidak stabil. Kecepatan akses dan kestabilan merupakan dua hal penting dan tidak dapat dipisahkan dalam menentukan kualitas jaringan komputer. kedua hal tersebut harus selalu dijaga agar kualitas jaringan tetap baik, dan jika terjadi gangguan dapat segera diketahui dan diperbaiki. Peran System Administrator jaringan menjadi sangat penting dalam menjaga kedua hal tersebut. FMIPA merupakan salah satu fakultas di Unesa Surabaya, terdiri dari lima (5) departemen dan 9 program studi. Tiap departemen terhubung dalam suatu jaringan serat optik, yang merupakan bagian dari jaringan kampus Unesa. Akses internet merupakan layanan yang paling banyak digunakan oleh seluruh dosen, staf dan mahasiswa. Berapapun bandwidth tidak akan mencukupi jika tidak ada pengaturan dan monitoring.

Monitoring jaringan komputer harus selalu dilakukan setiap waktu untuk menjamin jaringan dalam kondisi stabil dan jika terjadi gangguan dapat segera diketahui. Untuk jaringan skala besar dan komplek yang terdiri dari puluhan, ratusan bahkan ribuan perangkat, monitoring jaringan bukan pekerjaan yang mudah. Jika terdapat salah satu perangkat tidak tidak berjalan, maka akan memakan waktu yang lama untuk melakukan pengecekan satu persatu pada semua perangkat yang ada pada jaringan. Oleh karena itu diperlukan suatu sistem monitoring jaringan yang akan mengawasi setiap perangkat yang meliputi kegiatan pengecekan setiap perangkat pada kondisi up atau down, pengecekan traffic internet, pemetaan setiap hardware baik router maupun server. Sistem monitoring harus selalu aktif baik dengan pangawasan system administrator maupun tidak.

SNMP (Simple Network Management Protocol) adalah protocol yang telah menjadi standar industri dalam monitoring jaringan yang terdiri dari Network Management System (NMS) dan SNMP Agent [1]. NMS bertugas untuk mendapatkan dan pengolahan data dari perangkat jaringan yang dipantau. SNMP agent terimplementasi pada router, server dan perangkat jaringan lainnya. Hasil monitoring disajikan dalam bentuk grafik fluktuasi dari tiap agent SNMPT yang dipantau. Penelitian terkait monitoring jaringan antara lain: monitoring jaringan dengan the dude pada mikrotik [1], Efisiensi monitoring dan manajemen jaringan [2], keamanan monitoring jaringan dengan mobile agents [3], arsitektur manajemen trafik dan analisanya berbasis open source [4], implementasi SNMP dengan fitur peringatan dini dan mapping jaringan [5], dan network mapping sistem monitoring jaringan [6]. 


\section{METODE PENELITIAN}

Fokus penelitian ini adalah membangun sistem monitoring jaringan FMIPA Unesa berbasis protocol SNMP dengan menggunakan Cacti. Proses monitoring dilakukan secara terpusat dan berbasis web pada perangkat router, aktivitas koneksi internet, dan server. Sistem monitoring selalu mengawasi kondisi terkini jaringan yang disertai dengan pemetaan dan kondisi koneksi (link) antar perangkat. Terdapat notifikasi email akan dikirimkan kepada System Administrator jika terdapat gangguan pada jaringan. Arsitektur jaringan yang digunakan terlihat pada Gambar 1 .

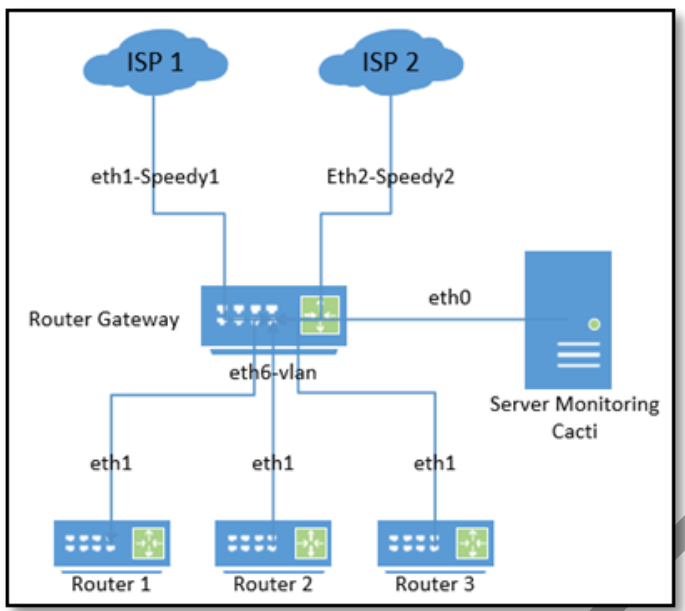

GAMBAR 1. ARSITEKTUR JARINGAN FMIPA

Pada Gambar 1, router berfungsi sebagai gateway yang terhubung ke penyedia jasa internet (ISP1, ISP2) melalui dua koneksi. Router gateway memiliki dua IP (Internet Protocol) publik, yang salah satunya digunakan untuk forward ke server monitoring Cacti sehingga bisa diakses dari luar jaringan melalui web. Karena terdapat dua koneksi yang dibagi ke router1, router2, dan router3 maka pada router gateway dilakukan proses load balancing. Monitoring yang dilakukan router gateway meliputi resource (memory, disk, processor), trafik internet, dan availability. Router 1, 2 dan 3 yang selanjutnya ditulis R1, R2, R3 berfungsi sebagai gateway yang menerima koneksi dari router gateway kemudian membagi ke client yang terhubung. Monitoring yang dilakukan pada R1, R2 dan R3 meliputi resource, traffic, availability, dan notifi-kasi email. Server Cacti berada tepat dibawah router gateway bertujuan agar dapat melakukan monitoring pada semua router yang terhubung ke router gateway.

Perangkat keras dan perangkat lunak yang digunakan dalam penelitian ini antara lain:

- 4 buah router yang terdiri dari satu jenis RB 1100AHx2 untuk router gateway, dan tiga jenis RB 951G-2HnD untuk R1, R2, dan R3.
- Virtual server yang menggunakan Ubuntu 14.04 sebagai server Cacti.

- Putty, untuk administrasi server.

Pengujian yang dilakukan pada penelitian ini antara lain:

1. Monitoring resource, meliputi penggunaan memory, disk, dan processor.

2. Avalability dan traffic (bandwidth)

Pengujian untuk uptime perangkat dan traffic (bandwidth).

3. Notifikasi down

Pengujian untuk notifikasi dari server Cacti melalui email ketika server down.

Pengujian dilakukan pada jaringan yang sebenarnya yakni jaringan internet di FMIPA Unesa, dengan arsitektur seperti terlihat pada Gambar 1. Skenario uji coba yang dilakukan antara lain:

1. Pengujian resource

Dilakukan untuk uji monitoring resource guna memantau status terkini resource dari hardware router yang di-monitoring. Hasilnya kemudian dibandingkan dengan hasil monitoring dari tools bawaan router.

2. Pengujian availability dan traffic (bandwidth).

Pengujian availability, jika dalam jangka waktu tertentu router tidak dapat terhubung dengan cacti maka router dinyatakan down. Sedangkan pada pengujian bandwidth dan traffic, Cacti akan mengumpulkan data hasil monitor berbasis protocol SNMP melalui graph. Pengujian akan dilakukan dengan mengecek apakah cacti dapat memonitor availability, traffic (bandwidth) dari setiap perangkat jaringan, kemudian hasilnya dibandingkan dengan monitoring availability, traffic (bandwidth) hasil monitoring yang ada pada internal router masing-masing yaitu dengan graphing.

3. Pengujian notifikasi email

Pengujian notifikasi dilakukan untuk mengetahui notifikasi saat host ada yang mati atau down. Proses pengujian dilakukan dengan melakukan percobaan pemutusan jaringan dengan 3 buat router yaitu R1, R2, dan R3 selama 5 menit. Jika Cacti mendeteksi adanya host yang down, maka akan memberikan notifikasi melalui email kepada email system administrator.

\section{HASIL DAN PEMBAHASAN}

Langkah pertama yang dilakukan pada penelitian ini adalah menyiapkan tools dan perangkat keras yang diperlukan. Tools yang dipasang (install) antara lain:

1. PHP, Apache dan MySQL

2. RRD Tools

3. SNMP dan SNMPD 
4. Cacti

5. Mail server SendMail

6. Plugin Cacti (monitor, weathermap, mikrotik, clog, thold)

Proses instalasi tools dilakukan secara online menggunakan manajemen paket perangkat lunak di debian, apt-get. Plugin Cacti yang telah terpasang dan diaktivasi dapat dilihat pada Gambar 2. Selain itu, juga dilakukan konfigurasi plugin, template graph, dan template mikrotik. Konfigurasi ini bertujuan agar data dari hardware mikrotik dapat diambil sehingga dapat ditampilkan dalam bentuk grafik.

\begin{tabular}{l} 
Plugin Management (Cacti Version: $\mathbf{0 . 8 . 8 b}$, Plugin Archite \\
Search: \\
\hline
\end{tabular}

GAMBAR 2. PLUGIN CACTI YANG TERPASANG

Langkah berikutnya adalah instalasi dan konfigurasi SNMP, SNMPD dan Cacti. Pengaturan yang dilakukan setelah instalasi SNMPT dan SNMPD meliputi rocommunity, syslocation, agentAddress dan syscontact. Selama proses instalasi Cacti, pengaturan yang dilakukan antara lain: penentuan web server (apache2), database cacti, password database. Pengaturan lain yang dilakukan pada Cacti adalah memilih tipe instalasi "New Install" dan Cacti akan melakukan proses pengecekan semua tools yang diperlukan sehingga laman login Cacti ditampilkan. Setelah login di Cacti, perlu dilakukan perubahan tipe poller menjadi spine kemudian dilakukan rebuild poller cache.

Seteleh Cacti berjalan baik, dilakukan konfigurasi plugin untuk melengkapi fitur. Plugin yang dipasang antara lain: monitor, thold, mikrotik, settings, clog, dan weathermap. Proses instalasi plugin dilakukan dengan unduh paket, ekstrak dan memindahkan ke direktori plugin dari Cacti.

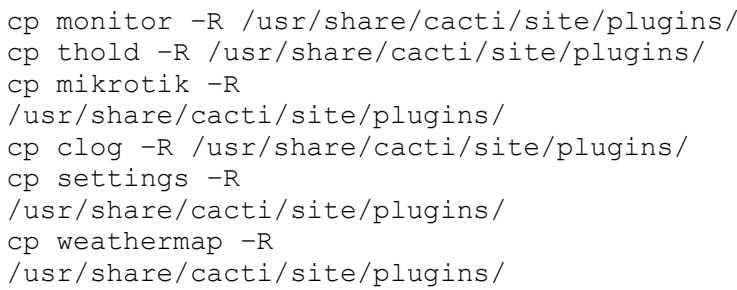

Plugin yang telah terpasang kemudian diaktifkan melalui aplikasi Cacti, pada menu plugin management. Plugin yang telah aktif terlihat pada Gambar 3. Agar plugin berjalan dengan baik, diatur juga hak akses pada direktori plugin menjadi 777.

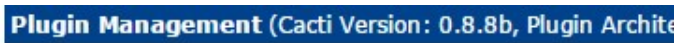

$$
\text { Search: }
$$

\begin{tabular}{lll}
\hline Actions & Name & Version \\
\hline (1) & Clog & 1.7 \\
(1) & Monitor & 1.3 \\
(1) & Settings & 0.71 \\
(1) & Mikrotik & 1.0 \\
(1) & Weathermap & $0.97 \mathrm{~b}$ \\
\hline & Thold & 0.5 \\
NOTE: Please sort by 'Load Order' to change plugin load ordering. \\
NOTE: SYSTEM plugins can not be ordered.
\end{tabular}

Setelah dipastikan semua plugin aktif, dilakukan konfigurasi antara lain:

1. Web server

Tujuannya adalah menjadikan Cacti menjadi default halaman web ketika pengguna mengakses server.

2. Weathermap

Dilakukan dengan memberikan hak akses 777 dengan opsi -R pada folder configs dan output agar dapat menjalankan pemetaan jaringan.

3. Router Gateway dan Router

Konfigurasi yang dilakukan adalah seperti Gambar 4 yakni penambahan device dan graph pada Cacti agar router gateway dapat dimonitor. Templates graph yang dipilih adalah disk space, memory, uptime, CPU utilization, dan jaringan WAN serta VLAN 6 yang menuju ke router 1, 2 , dan 3 .

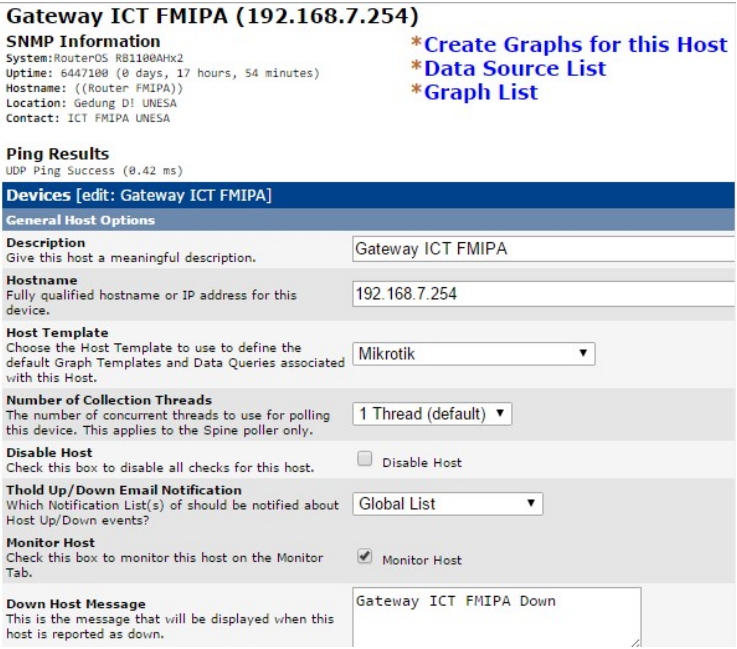

GAMBAR 4. KONFIGURASI GATEWAY PADA CACTI 
Selain pada gateway, juga dilakukan konfigurasi pada router 1, 2, dan 3. Konfigurasi yang dilakukan hampir sama dengan gateway, berbeda pada host yang dikonfigurasi, terlihat pada Gambar 5.

\section{R2 D1 FMIPA (192.168.33.232)}

\section{Host: R2 D1 FMIPA (192.168.33.232) V Graph Types:}

\section{Graph Templates}

\section{Graph Template Name}

Create: Mikrotik - IP - ARP Entries

Create: Mikrotik - IP - Routes

Create: Mikrotik - PPP - Active

Create: Mikrotik - System - Available Disk Space

Create: Mikrotik - System - CPU Load

Create: Mikrotik - System - Memory Usage

Create: Mikrotik - System - Uptime

Create: Mikrotik - Wireless - RegTable Connections

Create: (Select a graph type to create)

GAMBAR 5. KONFIGURASI ROUTER

4. Pemetaan Jaringan

Menggunakan editor weathermap, dilakukan penambahan topologi sesuai keadaan jaringan dan tiap perangkat jaringan disambungkan, seperti terlihat di Gambar 6.

5. Notifikasi Email

Konfigurasi sendmail untuk fitur notifikasi melalui email jika terdapat perangkat yang down atau tidak berfungsi.

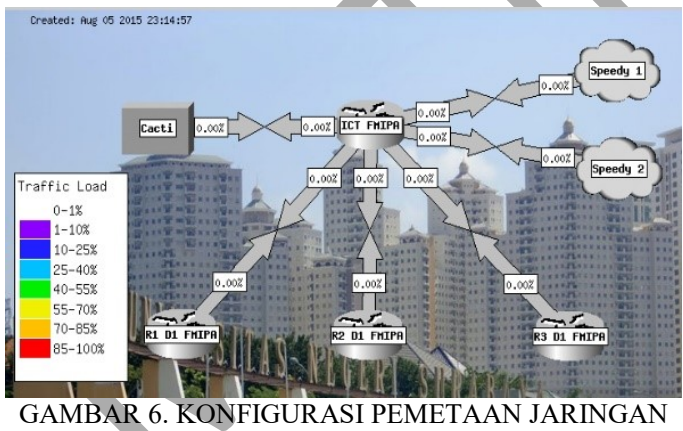

Pengujian dilakukan pada router 1, 2, 3 dan gateway. Aspek pengujian meliputi resource, bandwidth, availability, dan notifikasi. Hasil pengujian tiap aspek adalah sebagai berikut:

1. Pengujian Resource

Hasil dari monitoring resource yakni disk space, cpu usage, dan memory usage pada Router Gateway, dan hasil monitoring terlihat sama dengan kondisi real pada perangkat, namun pada disk space Cacti tidak dapat menangkap hasil monitoring karena parameter oid tidak mendapatkan data saat dilakukan monitoring, terlihat di Gambar 7.

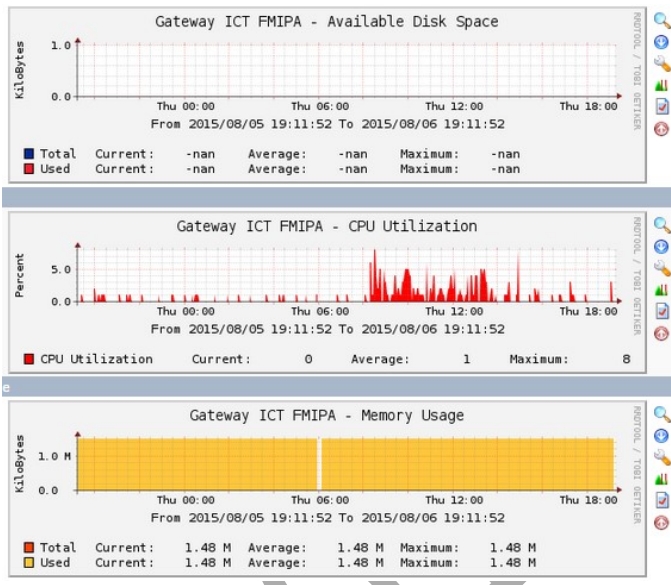

GAMBAR 7. RESOURCE MONITORING

2. Pengujian bandwidth

Hasil monitoring traffic pada router 1 yang merupakan salah satu WAN yang dimonitoring oleh Cacti, dan dapat tertangkap hasil monitoring dengan baik sesuai dengan kondisi real pada traffic perangkat, terlihat pada Gambar 8 .

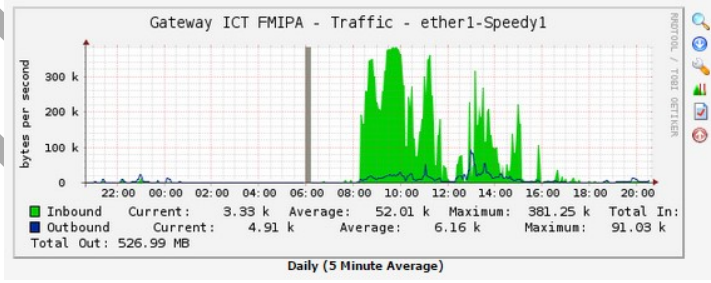

GAMBAR 8, BANDWITH MONITORING

3. Pengujian Availability

Cacti dapat menagkap dengan baik sesuai dengan uptime dari perangkat yang dimonitoring, terdapat pada Gambar 9.

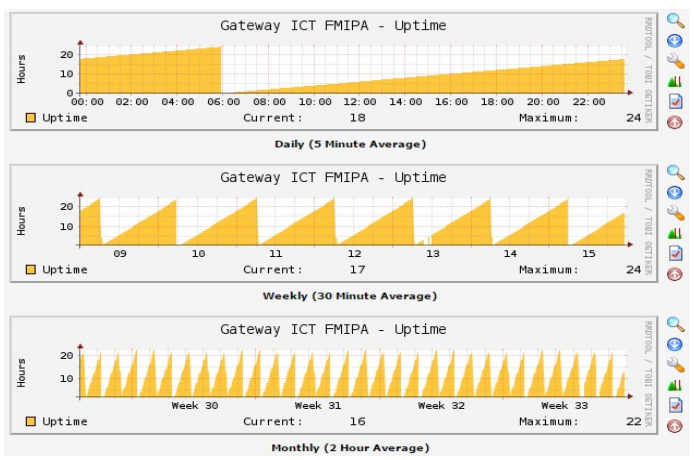

GAMBAR 9. AVAILABILITY MONITORING

4. Pengujian Notifikasi Email

Ketika koneksi dari router gateway ke router 1, 2, dan 3 diputus maka terjadi perubahan icon pada R1 D1 FMIPA, R2 D1 FMIPA, dan R3 D1 FMIPA yang ketiganya merupakan router 1,2 
dan 3 saat terjadi down. Ketika terjadi down, Cacti secara otomatis mengirimkan notifikasi down berupa email. Ketika host yang down hidup, maka icon down berubah menjadi recovering, dan notifikasi email dikirim yang berisi pesan bahwa host sudah hidup. Mekanisme tersebut dapat dilihat pada Gambar 10, 11, dan 12 .

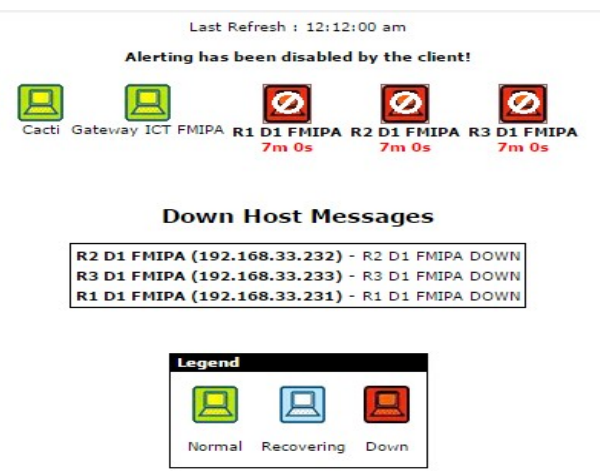

GAMBAR 10. NOTIFIKASI DOWN

Last Refresh : 12:15:04 am
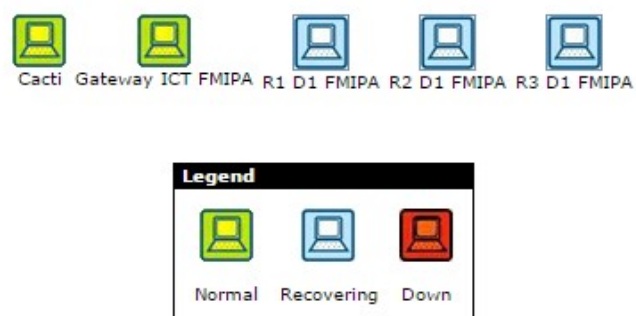

GAMBAR 11. NOTIVIKASI RECOVERING

Host Error Bos : R1 D1 FMIPA (192.168.33.231) kondisi sekarang DOWN

Ke wahyu.khamdani@yahoo.co.id

System Error: R1 D1 FMIPA (192.168.33.231) Sekarang DOWN
Alasan: Host did not respond to SNMP, UDP: Ping timed out

Rata-rata Respon Server : $2.4 \mathrm{~ms}$

Ketersediaan Sistem: 99.519

Total Cek Gagal: 36

Tanggal Terakhir Diperiksa DOWN : 2015-08-03 00:05:00

Host Sebelumnya UP Selama: $20 \mathrm{~d}$ 9h $35 \mathrm{~m} 25 \mathrm{~s}$

NOTE

Balas, Balas Semua atau Teruskan | Lebih lanjut

GAMBAR 12. NOTIFIKASI EMAIL KETIKA DOWN

\section{KESIMPULAN}

Aplikasi Cacti dapat melakukan monitoring kondisi jaringan dan bandwith pada setiap perangkat yang ada dengan bantuan protocol SNMP. Hal ini ditunjang dari hasil uji coba monitoring pada beberapa router yang menghasilkan grafik dari traffic dan bandwidth yang menunjukkan hasil yang mendekati sama dengan kondisi real. Aplikasi ini dapat memberikan notifikasi berupa email jika terdapat perangkat yang mati, serta Cacti dapat menghasilkan pemetaan jaringan sesuai dengan skema jaringan dan traffic yang real time. Untuk pengembangan lebih lanjut, notifikasi dapat juga dilakukan melalui SMS.

\section{REFERENSI}

[1] M. Nugroho, A. Affandi and D. Suprajitno Rahardjo, "Rancang Bangun Aplikasi Monitoring Jaringan Menggunakan SNMP (Simple Network Management Protocol) dengan sistem peringatan dini dan Mapping Jaringan," POMITS, pp. 2301-9271, Vol.3, No. 12014

[2] R. Agustina, M. Zaini Yusuf, I. Purnama and M. Nuril Anwar, "Monitoring Jaringan menggunakan Mikrotik OS dan The Dude," Jurnal Teknologi, Volumen 6, 2013.

[3] R. Khan, S. Ullah Khan, R. Zaheer and M. Inayatullah Babar, "An Efficient Network Monitoring and Management System," International Journal of Information and Electronic Engineering, Vol.3 No 12013.

[4] L. Carvalho and N. Dmello, "Secure Network Monitoring System using Mobile Agents," IJMER, pp. 1850-1853, Vol.3, Issue 3, May-June 2013.

[5] O. Abiona, T. Aladesanmi and C. Onime, "A Scalable Architecture for Network Traffic Monitoring and Analysis Using Free Open Source Software," IJCNS, pp. 528-539, September 2009.

[6] V. Anong Dian Hutama, A. Affandi and E. Setijadi, "Rancang Bangun Network Mapping Sistem Monitoring Jaringan," POMITS, pp. 1-6, Vol.1 No.1 2013 